\title{
Loop-mediated isothermal amplification
} (LAMP) assays targeting $18 \mathrm{~S}$ ribosomal RNA genes for identifying $P$. vivax and $P$. ovale species and mitochondrial DNA for detecting the genus Plasmodium

Xi Chen ${ }^{1,2 \dagger}$, Jiaqi Zhang ${ }^{2,3 \dagger}{ }^{\text {, Maohua Pan }}{ }^{4}$, Yucheng Qin ${ }^{4}$, Hui Zhao ${ }^{2}$, Pien Qin ${ }^{4}$, Qi Yang ${ }^{2}$, Xinxin Li², Weilin Zeng ${ }^{2}$, Zheng Xiang ${ }^{2}$, Mengxi Duan ${ }^{2}$, Xiaosong Li ${ }^{2}$ Xun Wang ${ }^{2}$, Dominique Mazier ${ }^{5}$, Yanmei Zhang ${ }^{2}$, Wei Zhao ${ }^{2}$, Benjamin M. Rosenthal ${ }^{6}$, Yaming Huang ${ }^{2,7^{*}}$ and Zhaoging Yang ${ }^{2 *}$

\begin{abstract}
Background: Loop-mediated isothermal amplification (LAMP) has been widely used to diagnose various infectious diseases. Malaria is a globally distributed infectious disease attributed to parasites in the genus Plasmodium. It is known that persons infected with Plasmodium vivax and $P$. ovale are prone to clinical relapse of symptomatic bloodstage infections. LAMP has not previously been specifically evaluated for its diagnostic performance in detecting $P$. ovale in an epidemiological study, and no commercial LAMP or rapid diagnostic test (RDT) kits are available for specifically diagnosing infections with P. ovale.

Methods: An assay was designed to target a portion of mitochondrial DNA (mtDNA) among Plasmodium spp., the five human Plasmodium species and two other assays were designed to target the nuclear 185 ribosomal DNA gene (18S rDNA) of either $P$. vivax or $P$. ovale for differentiating the two species. The sensitivity of the assays was compared to that of nested PCR using defined concentrations of plasmids containing the target sequences and using limiting dilutions prepared from clinical isolates derived from Chinese workers who had become infected in Africa or near the Chinese border with Myanmar.

Results: The results showed that $10^{2}$ copies of the mitochondrial target or $10^{2}$ and $10^{3}$ copies of 185 rDNA could be detected from Plasmodium spp., P. vivax and P. ovale, respectively. In 279 clinical samples, the malaria Pan mtDNA LAMP test performed well when compared with a nested PCR assay (95\% confidence interval [Cl] sensitivity $98.48-100 \%$; specificity $90.75-100 \%)$. When diagnosing clinical cases of infection with P. vivax, the 185 rDNA assay demonstrated an even great sensitivity (95.85-100\%) and specificity (98.1-100\%). The same was true for clinical infections with P. ovale (sensitivity 90.76-99.96\%; specificity 98.34-100\%). Using plasmid-positive controls, the limits of detection of Malaria Pan, 185 rDNA P. vivax and 185 rDNA P. ovale LAMP were 100-, 100- and tenfold lower than those of PCR, respectively.
\end{abstract}

\footnotetext{
*Correspondence: 1724501964@qq.com; zhaoqingy92@hotmail.com

${ }^{\dagger} \mathrm{Xi}$ Chen and Jiaqi Zhang contributed equally to this work

2 Department of Pathogen Biology and Immunology, Kunming Medical

University, Kunming 650500, Yunnan, People's Republic of China

Full list of author information is available at the end of the article
}

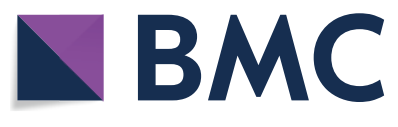

(c) The Author(s) 2021. This article is licensed under a Creative Commons Attribution 4.0 International License, which permits use, sharing, adaptation, distribution and reproduction in any medium or format, as long as you give appropriate credit to the original author(s) and the source, provide a link to the Creative Commons licence, and indicate if changes were made. The images or other third party material in this article are included in the article's Creative Commons licence, unless indicated otherwise in a credit line to the material. If material is not included in the article's Creative Commons licence and your intended use is not permitted by statutory regulation or exceeds the permitted use, you will need to obtain permission directly from the copyright holder. To view a copy of this licence, visit http://creativeco mmons.org/licenses/by/4.0/. The Creative Commons Public Domain Dedication waiver (http://creativecommons.org/publicdomain/ zero/1.0/) applies to the data made available in this article, unless otherwise stated in a credit line to the data. 
Conclusion: The novel LAMP assays can greatly aid the rapid, reliable and highly sensitive diagnosis of infections of Plasmodium spp. transmitted among people, including P. vivax and P. ovale, cases of which are most prone to clinical relapse.

Keywords: LAMP, Genus Plasmodium spp., Plasmodium vivax, Plasmodium ovale

\section{Background}

Malaria, transmitted by female Anopheles mosquitoes, is a major global burden to human health and welfare, with an estimated 228 million cases and 405 thousand deaths reported in 2018 [1]. Anopheline vectors transmit, from person to person, malaria derived from any of four parasite species in the genus Plasmodium: Plasmodium falciparum, $P$. vivax, $P$. malariae and $P$. ovale (including $P$. ovale curtisi and $P$. ovale wallikeri). Of these, $P$. vivax is the most widespread and responsible for the majority of malaria infections outside of Africa, with 5.9 million clinical cases reported in 2018 [1]. Plasmodium vivax is endemic in Southeast Asia, where it is generally assumed to be the causative agent of malaria [2,3]. Plasmodium ovale is mainly restricted to West Africa, where it generally has a low prevalence [4]. Among the Plasmodium species of human malaria, these latter two are distinctive by sharing a dormant hypnozoite stage in hepatocytes that can cause relapse of symptomatic blood-stage infections weeks, months or even years after the primary infection $[5,6]$. The administration of primaquine can eliminate hypnozoites in the liver [7]. It is therefore important for clinicians to identify whether either of these two species is present, so as to promptly initiate the proper therapeutic regimen.

The prompt and accurate diagnosis of malaria constitutes a major technical challenge [8]. Delayed diagnosis and therapy can exacerbate the severity of the disease. Misdiagnosis of the Plasmodium species results in improper use of anti-malarial drugs, worsening the spread of drug resistance. Furthermore, mixed infections comprised of more than one species of parasite are often not recognized, thereby preventing accurate diagnosis and treatment [9].

Traditional malaria diagnosis employs microscopic examination of thin and thick blood smears. Although microscopy can be used to diagnose the density and developmental stages of each parasite species, it is an arduous procedure and demands high technical proficiency. False negative diagnoses, most common when parasitemia is low [10] (for example after treatment), impedes proper case management.

Other diagnostic techniques employ antigen capture. The main targets for antigen capture methods include the P. falciparum-specific histidine-rich protein-2 (PfHRP2), P. falciparum-specific lactate dehydrogenase $(P f-p L D H)$,
P. vivax-specific lactate dehydrogenase $(P v p L D H)$, pan$p L D H$ and pan-aldolase. The sensitivity and specificity of these assays are poor, especially for mixed infections, and existing methods do not diagnose infections with $P$. ovale, P. malariae or P. knowlesi [11].

A third family of methods employs PCR assays to identify nucleic acids of the parasite. PCR assays have a higher sensitivity and specificity than antigen capture methods, detecting as few as $1-5$ protozoa/ $\mu$ blood, and are able to diagnose mixed infections. However, they are time-consuming (typically requiring 3-4 h of run time on a thermocycler) and costly, and require sophisticated experimental testing equipment and professional technicians. Consequently, PCR assays are of limited utility in many regions endemic for malaria [12]. Therefore, it is of great importance to develop a simple method for the rapid and accurate detection of Plasmodium species.

Fluorescence in situ hybridization (FISH) has also proven effective in diagnosing human malaria [13]. This cytogenetic technique is based on the detection of DNA or RNA following hybridization with complementary sequences labeled with fluorescent probes and can used in combination with microscopy without the need for nucleic acid amplification. FISH has been documented as having a high sensitivity (98\%) for detecting Plasmodiun infections, detecting live parasites, with a requirement for 55-65 protozoa/ $\mu$ l blood [14]. Microscopy skills are widely available in many malaria-endemic countries, but specialized skills are required for fluorescent microscopy, which may limit use of the FISH in certain endermic areas.

Loop-mediated isothermal amplification (LAMP), first described in 2000 [15], employs isothermal cyclic strand displacement DNA synthesis using Bst DNA polymerase. Such tests can be performed at $60-65{ }^{\circ} \mathrm{C}$ in $1 \mathrm{~h}$, using a simple water bath. Unlike PCR, it does not require DNA templates to be denatured. It uses a series of six primers, of which four target their own templates and two loop primers accelerate production of the product. As amplification products accumulate, they can be visualized by eye as an increase in turbidity and fluorescence under illumination by ultraviolet (UV) light [16]. The LAMP technique is widely used in the diagnosis of various infectious diseases, such as tuberculosis, toxoplasmosis and trichomoniasis [17-19]. LAMP has been used in malaria diagnosis since 2007 [16]. 
The Eiken Loopamp ${ }^{\mathrm{TM}}$ MALARIA Pan Detection kit (Eiken Chemical Company, Tokyo, Japan) and the Illumigene Malaria Plus test (Meridian Bioscience Inc., Cincinnati, $\mathrm{OH}, \mathrm{USA}$ ) are the most widely-used commercial LAMP kits for detecting malaria. However, the Eiken Loopamp $^{\mathrm{TM}}$ MALARIA Pan Detection kit was recently found to lack the reliability required for diagnostic laboratories, especially given limited sensitivity when parasitemia is low [20]. In addition, published LAMP primers intended to be specific for $P$. ovale [16] were reported to yield a high risk of cross reactions [20]. To date, a LAMP assay or rapid diagnostic test (RDT) specific for detecting $P$. ovale is not commercially available, nor has any report documented LAMP assay performance on clinical samples containing P. ovale.

In this study, we developed and tested novel LAMP assays to detect all species of all human malaria and to differentially diagnose $P$. vivax and $P$. ovale infections, using a positive control plasmid construct as well as clinical cases of malaria imported to China as a basis to evaluate sensitivity and specificity. We sought to establish, for resource-limited conditions, an accurate and rapid method to diagnose any human malaria infection and also identify when species prone to causing clinical relapse are present. We also tried to reduce the cost of the assay to make it widely available.

\section{Methods}

Collection of clinical samples and microscopic examination All clinical samples for use in the study were collected from patients with suspected malaria with febrile symptoms. The clinical samples were obtained from the Department of Infectious Diseases in Shanglin Hospital, Shanglin County, Guangxi Province, China and Tengchong County (China-Myanmar border), Yunnan Province, China. The clinical subjects were Chinese migrant workers who had returned from Africa or Myanmar within the preceding 2 weeks. All clinical samples were diagnosed immediately by microscopic examination and sent to Kunming Medical University for molecular studies. Reference Plasmodium falciparum (strain 3D7) cultured in vitro and the Strain $\mathrm{H}$ clone of Plasmodium knowlesi were obtained from the Malaria Research and Reference Reagent Resource Center. Toxoplasma gondii, a protozoan infecting nucleated cells at a high infection rate in humans, obtained from the Department of Pathogen Biology and Immunology, Kunming Medical University, was also used for testing the novel primers (as a negative control). Thin and thick blood films were prepared and Giemsa-stained for microscopy examination. All slides were read by skilled microscopists; thin films were read under $10 \times 100$ magnification. Species were identified by observing characteristic morphology in thin films. The parasite density was calculated in thick films according to the numbers of parasites per 500 leukocytes, assuming 8000 leukocytes/ $\mu$ l blood.

\section{DNA extraction and nested PCR for identifying Plasmodium species}

Genomic DNA was prepared using the Roche High Pure PCR Template Preparation kit (Roche Diagnostics, Indianapolis, IN, USA). In brief, $200 \mu \mathrm{l}$ whole blood, $200 \mu \mathrm{l}$ Binding Buffer and $40 \mu \mathrm{l}$ proteinase $\mathrm{K}$ were heated at $70{ }^{\circ} \mathrm{C}$ for $10 \mathrm{~min}$. Then, $100 \mu \mathrm{l}$ of isopropanol, $500 \mu \mathrm{l}$ of Inhibitor Removal Buffer and $500 \mu \mathrm{l}$ of Washing Buffer were added sequentially. After each addition, the solution was centrifuged at $8000 \mathrm{rpm}$ for $1 \mathrm{~min}$. A $50-\mu \mathrm{l}$ aliquot of elution buffer was used to elute the DNA, and the extracted DNA was stored at $-20{ }^{\circ} \mathrm{C}$ until use. Aliquots of $1 \mu \mathrm{l}$ DNA were used to run the nested PCR for identifying the five human Plasmodium species according to previously reported methods [21, 22].

\section{LAMP primer design}

LAMP Designer 1.15 was used to identify mtDNA targets conserved among all five species (Malaria Pan assay). According to the LAMP primer design requirement, the targeting reference sequences should be shorter than $300 \mathrm{bp}$. The $18 S$ rDNA gene sequences retrieved from $P$. vivax and $P$. ovale were used for designing primers for $P$. vivax and $P$. ovale. Reference sequences downloaded were $m t D N A$ sequences from P. falciparum [Genbank no. M99416.1], P. vivax [Genbank no. KF668441.1], P. ovale curtisi [Genbank no. HQ712052.1], P. ovale wallikeri [Genbank no. HQ712053.1], P. malariae [Genbank no. AB489194.1] and P. knowlesi [Genbank no. AY722797.1] and $18 S$ rDNA sequences from $P$. vivax [Genbank no. DQ162604.1], P. ovale curtisi [Genbank no. JF894405.1] and $P$. ovale wallikeri [Genbank no. JF894406.1].

\section{Establishment of a closed-tube visualization LAMP system} A set of LAMP primers consisting of F3, B3, FIP, BIP, LF and LB primers was used (Table 1 ). The $12.5-\mu \mathrm{l}$ reaction mixture consisted of $1.6 \mu \mathrm{M}$ FIP and BIP, $0.8 \mu \mathrm{M} \mathrm{LpF}$ and $\mathrm{LpB}, 0.2 \mu \mathrm{M}$ F3 and B3, $4 \mathrm{mM} \mathrm{MgSO} 4,1.25 \mu \mathrm{L}$ buffer $10 \times, 0.5 \mu \mathrm{L}$ Bst DNA polymerase (New England Biolabs, Ipswich, MA, USA), $1 \mu$ template DNA, $0.4 \mu \mathrm{M}$ Calcein$\mathrm{MnCl}_{2}$ dye and $6 \mu \mathrm{l}$ double-distilled water (DDW). The LAMP reaction systems were performed in capped PCR tubes in a water bath at $65^{\circ} \mathrm{C}$, for $60 \mathrm{~min}$ without further manipulation. After cooling, each tube was examined by eye under visible light to determine whether the contents had changed from clear and orange to green and turbid, and whether under UV light the solution had become fluorescent. For confirmation, five samples of each Plasmodium species were tested by LAMP primers and analyzed 
Table 1 Primer sets of the loop-mediated isothermal amplification for detection of Malaria Pan, Plasmodium vivax and P. ovale

\begin{tabular}{|c|c|c|}
\hline Species & Primer & Sequence $\left(5^{\prime}-3^{\prime}\right)$ \\
\hline \multirow[t]{6}{*}{ Malaria Pan LAMP assay } & F3 & TGTCAACTACCATGTTACGAC \\
\hline & B3 & AACGGTCCTAAGGTAGCAA \\
\hline & FIP (F1c-F2) & TACGGCCCGACGGTAAGATCGTAACCATGCCAACAC \\
\hline & $\mathrm{BIP}(\mathrm{B} 1 \mathrm{c}-\mathrm{B} 2)$ & AGGAGTCTCACACTAGCGACAAAATTCCTTGTCGGGTAATCTC \\
\hline & LPF & CTGAGCACCTTAACTTCCCTAA \\
\hline & LPB & TACACCGTTCATGCAGGAC \\
\hline \multirow[t]{6}{*}{ P. vivax } & F3 & CTAATTAGCGGTAAGTACGACA \\
\hline & B3 & AGCCTAGTTCATCTAAGGACA \\
\hline & $\mathrm{FIP}(\mathrm{F} 1 \mathrm{c}-\mathrm{F} 2)$ & ACCAAACGCATCAGCTATTCGTATGTCGGATTGGATCTGGA \\
\hline & $\mathrm{BIP}(\mathrm{B} 1 \mathrm{c}-\mathrm{B} 2)$ & TTACTTGGCTTATCGTACCGTTCAGACCTGTTGTTGCCTT \\
\hline & LPF & CACCGACACGAAGTATAATTGC \\
\hline & LPB & GCTTCTTAGAGGAACGATGTGT \\
\hline \multirow[t]{6}{*}{ P. ovale } & F3 & CGAGTTTCTGACCTATCAGC \\
\hline & B3 & GCTGGCACCAGACTTG \\
\hline & $\mathrm{FIP}(\mathrm{F} 1 \mathrm{C}-\mathrm{F} 2)$ & GATGTGGTAGCTATTTCTCAGGCTCCCTAACATGGCTATGACGG \\
\hline & $\mathrm{BIP}(\mathrm{B} 1 \mathrm{C}-\mathrm{B} 2)$ & GCAGCAGGCGCGTAAATTACAACCATGAAATGGCCTTGT \\
\hline & LPF & TCTCCGGAATCGAACTCTAATTC \\
\hline & LPB & TCTAAAGAAGAGAGGTAGTGACAAG \\
\hline
\end{tabular}

LAMP loop-mediated isothermal amplification

by $1.5 \%$ gel electrophoresis. Following electrophoresis, successful amplifications could be identified by the presence of continuous trapezoidal bands.

\section{Construction of positive control plasmid DNA}

The sensitivity of LAMP primer assays was evaluated by using defined templates derived from plasmids constructed to include the conserved mitochondrial target (pMD19-Pan), the $18 S$ sequence for P. vivax (pMD19-Pv) or the $18 S$ sequence for $P$ ovale (pMD19-Po). The target DNA sequence was amplified with F3 and B3 LAMP primers by PCR. The amplification reactions were performed in $25 \mu \mathrm{l}$ of PCR mixture with $1 \mu \mathrm{l}$ DNA template, $0.5 \mu \mathrm{M}$ of each F3 and B3 primer, $12.5 \mu \mathrm{l}$ Master Mix (Premix Taq; Takara Taq Version 2.0 [Takara Bio Inc., Kusatsu, Japan]) and 9.5 $\mu$ LDW. The PCR cycling conditions for the amplification of the Malaria Pan mtDNA gene sequence were: $94{ }^{\circ} \mathrm{C}, 3 \mathrm{~min}$; then $94{ }^{\circ} \mathrm{C} / 30 \mathrm{~s}$, $51.5{ }^{\circ} \mathrm{C} / 30 \mathrm{~s}, 72{ }^{\circ} \mathrm{C} / 1 \mathrm{~min}$ for 30 cycles; and a final extension at $72{ }^{\circ} \mathrm{C}$ for $5 \mathrm{~min}$. The PCR cycling conditions for the amplification of the $P$. vivax $18 S$ rDNA gene sequence were: $94{ }^{\circ} \mathrm{C}, 3 \mathrm{~min}$; then $94{ }^{\circ} \mathrm{C} / 30 \mathrm{~s}, 52.1{ }^{\circ} \mathrm{C} / 30 \mathrm{~s}$, $72{ }^{\circ} \mathrm{C} / 1 \mathrm{~min}$ for 30 cycles; and a final extension at $72{ }^{\circ} \mathrm{C}$ for $5 \mathrm{~min}$. The PCR cycling conditions for the amplification of $P$. ovale $18 S \mathrm{rDNA}$ gene sequence were: $94{ }^{\circ} \mathrm{C}$ for $3 \mathrm{~min}$; then $94{ }^{\circ} \mathrm{C} / 30 \mathrm{~s}, 50{ }^{\circ} \mathrm{C} / 30 \mathrm{~s}, 72{ }^{\circ} \mathrm{C} / 1 \mathrm{~min}$ for 30 cycles; and a final extension at $72{ }^{\circ} \mathrm{C}$ for $5 \mathrm{~min}$. Each amplified product was sequenced and confirmed by BLAST search to correspond to the intended analyte. The target DNA fragments were then cloned into the pMD19$\mathrm{T}$ Vector (Takara Bio Inc.); three recombinant plasmids were identified based on blue-white color selection.

\section{Limits of detection, analytical sensitivity and specificity of LAMP assays}

Each recombinant plasmid was quantified using a NanoDrop ND-1000 spectrophotometer (Thermo Fisher Scientific, Waltham, MA, USA). Ten-fold serial dilutions were performed to produce plasmid concentrations as follows: pMD19-Pan from $1.08 \times 10^{9}$ to $1.08 \times 10^{1}$ copies/ $\mu \mathrm{l}$, pMD19- $P v$ from $1.05 \times 10^{9}$ to $1.05 \times 10^{1}$ copies $/ \mu \mathrm{l}$ and pMD19-Po from $1.07 \times 10^{9}$ to $1.07 \times 10^{1}$ copies $/ \mu$ l.

Another means to compare the sensitivity of LAMP to nested PCR used a series of twofold dilutions of DNA extracted from clinical isolates from patients with $P$. falciparum, $P$. vivax, $P$. ovale curtisi, $P$. ovale wallikeri and P. malariae infection. The minimum concentration from which positive reactions resulted from each amplification approach was thereby determined.

The fluorescent quantitative LAMP consisted of a 12.5$\mu \mathrm{l}$ reaction mixture with $1.6 \mu \mathrm{M}$ FIP and BIP, $0.8 \mu \mathrm{M} \mathrm{LpF}$ and $\mathrm{LpB}, 0.2 \mu \mathrm{M}$ F3 and B3, $4 \mathrm{mM} \mathrm{MgSO}_{4}, 1.25 \mu \mathrm{L}$ Buffer $10 \times, 0.5 \mu \mathrm{L}$ Bst DNA polymerase (New England Biolabs), $1 \mu \mathrm{l}$ template DNA, $0.25 \mu \mathrm{l} 5 \times$ SYBR green I dye (Takara Bio Inc.) and $6 \mu \mathrm{lDDW}$. The reaction was performed in an isothermal device at $65{ }^{\circ} \mathrm{C}$ for $1 \mathrm{~h}$ using the QuantStudio 6 Flex thermocycler (Thermo Fisher Scientific). LAMP reactions were also performed as described above 
with Calcein- $\mathrm{MnCl}_{2}$ dye. PCR analyses were also performed on these positive control plasmid templates. All clinical samples and the DNA templates of Toxoplasma gondii were used in LAMP reactions using three sets of primers. As a control, patent LAMP primers (targeting the $18 S$ rDNA gene) were also employed [16]. The LAMP primers and reagents were stored separately at $-20{ }^{\circ} \mathrm{C}$ and prepared at room temperature before use.

\section{Statistical analysis}

The clinical sensitivities, specificities and limits of detection (LODs) of $m t D N A$ Malaria Pan LAMP, $18 S r D N A$ $P$. vivax LAMP and $P$. ovale LAMP were determined by considering nested PCR as the gold standard following previously reports [16, 20, 23]. Statistical comparisons were performed using SPSS version 20.0 software (SPSS IBM Corp., Armonk, NY, USA).

\section{Results}

\section{Novel LAMP primers design}

Primers were designed (Table 1) that were capable of amplifying a conserved portion of the mtDNA from all five species and to design primers specific to the $18 \mathrm{~S}$ rDNA of either $P$. vivax or $P$. ovale (Table1). The results were observed by the naked eye with UV light, on a Gel imager or analyzed by gel electrophoresis if needed. No cross-reactions or false positives were observed (Fig. 1).

\section{LOD and sensitivity of LAMP primers}

Using the Malaria Pan LAMP assay directed at a conserved portion of mtDNA, as few as $10^{2}$ copies of the positive control plasmid resulted in visibly positive reactions. By this criterion, as few as $10^{2}, 10^{3}$ plasmid copies/ $\mu \mathrm{l}$ of the $18 S$ rDNA of $P$. vivax and P. ovale, respectively, could be detected by the new LAMP assay. Analysis of amplification curves in these LAMP reactions lead to the same conclusion. By contrast, PCR assays required $10^{4}$ copies/ $\mu$ target sequences to yield visible amplification products. By comparing the copies of plasmids $/ \mu \mathrm{l}$, the LOD of PCR was 100-fold higher than that of Malaria Pan LAMP assay and $18 S$ rDNA P. vivax LAMP and tenfold higher than that of $18 S$ rDNA P. ovale LAMP (Fig. 2).

Another means to compare the sensitivity of LAMP to PCR used a series of twofold dilutions of DNA extracted from the clinical isolates. As was true for nested PCR, each new LAMP assay was found capable of detecting $<5$ parasites $/ \mu \mathrm{l}$, and no significant difference was found between the results of LAMP and nested PCR when using diluted clinical isolates. Specifically, the LOD was found to be 3.73, 3.79 and 4.15 parasites/ $\mu$ l for the mtDNA Malaria Pan LAMP assay, the $18 S$ rDNA P. vivax LAMP assay and the $18 S$ rDNA P. ovale LAMP assay, respectively. This was found to be comparable to the values obtained in the nested PCR assays (3.95, 4.58 and 4.54 parasites $/ \mu \mathrm{l} ; P=0.34,0.42$ and 0.36 , respectively).

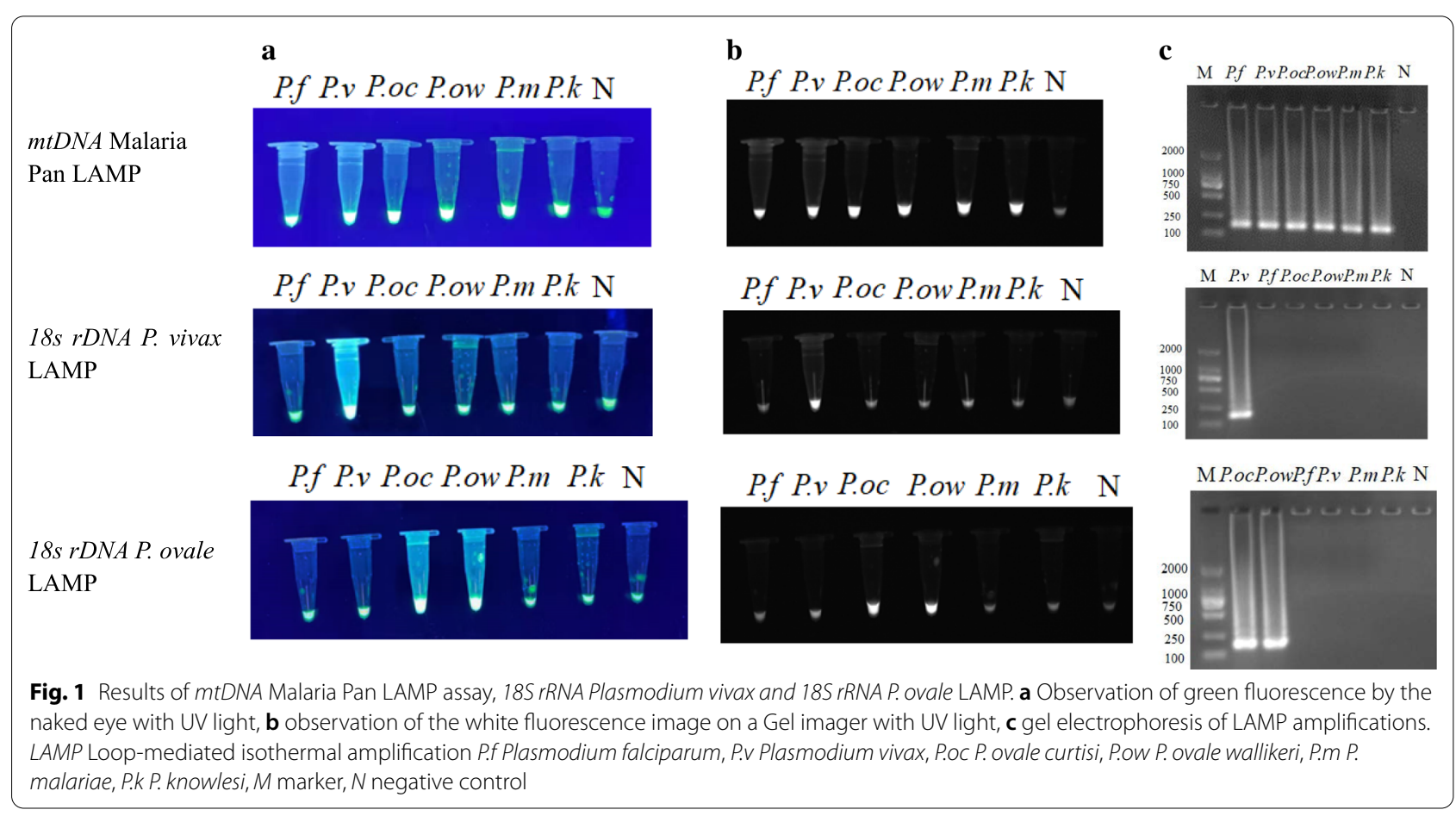




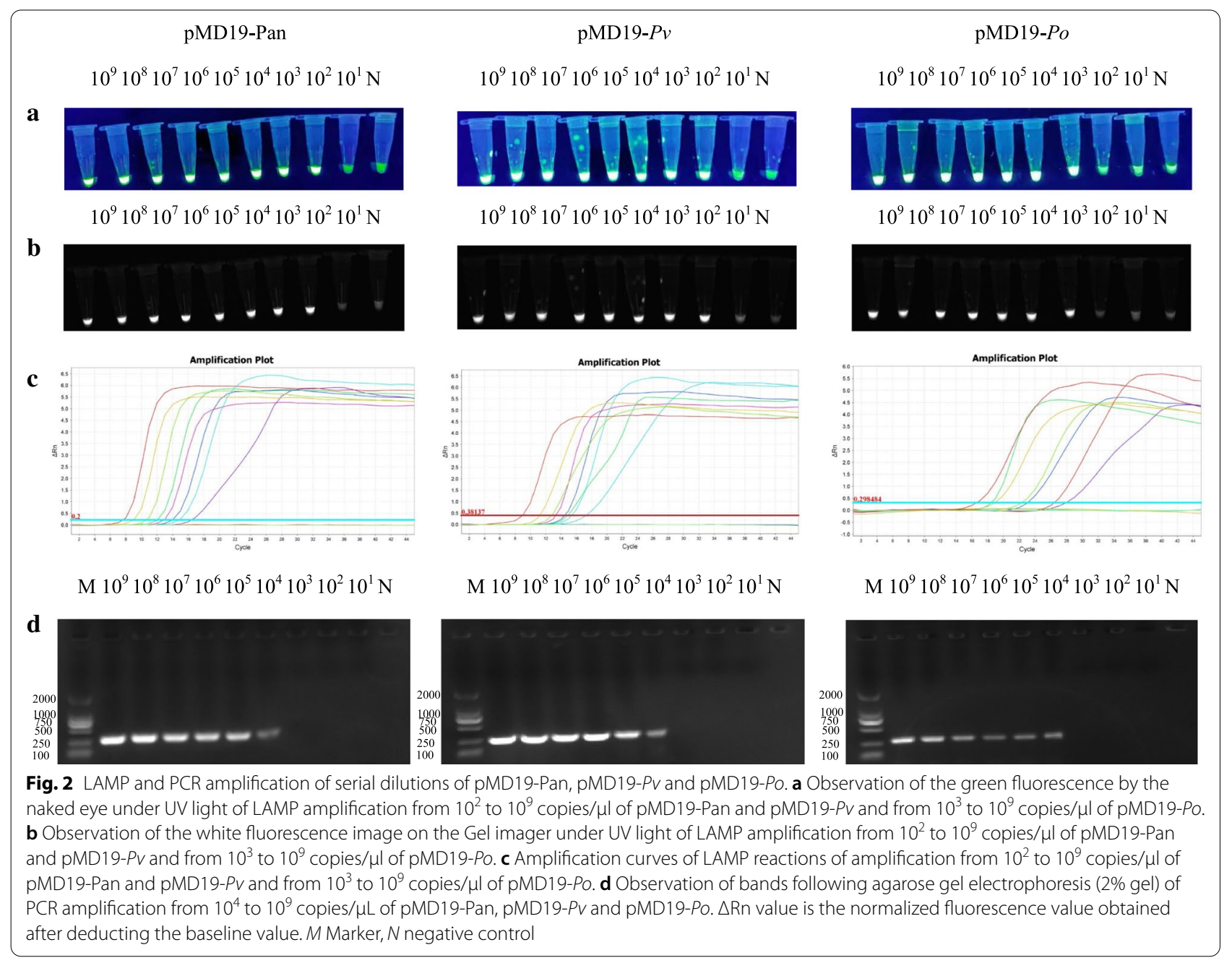

\section{Clinical samples studied performance}

A total of 279 clinical blood samples were collected from patients suspected of being infected with malaria. Parasite densities in these clinical samples, as estimated by microscopic examination, ranged from 0 to 125,240 parasite/ $\mu$ l blood. of these 279 blood samples, 208 were confirmed by microscopy to be malaria-positive cases and 241 were confirmed by nested PCR to be malaria-positive cases. Of the positive cases, 75 cases of $P$. vivax were in persons from Myanmar; the rest were in persons from Africa. All samples were tested by the $m t D N A$ Malaria Pan LAMP assay, and the results corresponded exactly to the outcomes of the nested PCR assays (sensitivity and specificity $=100 \%$, LOD is $3.73 \pm 0.33$ parasites/ $\mu \mathrm{L})$. The $18 S$ rDNA LAMP assay for $P$. vivax detected all 87 samples that tested positive for $P$. vivax by nested PCR, and was negative for all 192 samples judged negative by nested PCR for P. vivax (sensitivity and specificity $=100 \%$, LOD is $3.79 \pm 0.71$ parasites $/ \mu \mathrm{L}$ ). The $18 \mathrm{~S}$ rDNA LAMP assay for $P$. ovale detected 57 of 58 isolates assessed positive by nested PCR, and assessed all 221 isolates negative that likewise tested negative by nested PCR (sensitivity $=98.28 \%$, specificity $=100 \%$, LOD is $4.15 \pm 0.36$ parasites $/ \mu \mathrm{L}$ ) (Table 2 ).

The LAMP assays were assessed to be more sensitive than microscopy. Infection was diagnosed by microscopy in only 201 of the 241 samples deemed positive by the Malaria Pan LAMP assay (sensitivity $=81.6 \%$ ); of the 38 samples deemed negative for infection by the Malaria Pan LAMP assay, microscopy identified only 31 (81.6\%) as negative. Microscopy was positive for 78 of 87 clinical isolates testing positive by the LAMP assay for $P$. vivax (sensitivity $=89.7 \%$ ) and microscopy was positive for 44 of 58 infections testing positive for the LAMP assay for $P$. ovale (sensitivity $=75.9 \%$ ). Among the 221 samples deemed negative for $P$. ovale by the LAMP test, microscopy identified 201 (91\%) as negative for $P$. ovale. Overall, the LAMP tests provided greater correspondence to results from nested PCR and were deemed of greater diagnostic value than microscopy $(P<0.05)$. 
Table 2 Results as diagnosed by microscopic examination, nested PCR and malaria LAMP PAN assay

\begin{tabular}{|c|c|c|c|c|c|}
\hline Plasmodium species & Microscopy $($ cases, $n)$ & PCR (cases, $n)$ & $\begin{array}{l}\text { Malaria Pan LAMP } \\
(\text { cases, } n)\end{array}$ & $\begin{array}{l}\text { P. vivax LAMP (cases, } \\
\text { n) }\end{array}$ & $\begin{array}{l}\text { P. ovale } \\
\text { LAMP } \\
\text { (cases, } n \text { ) }\end{array}$ \\
\hline Plasmodium genus & & & 241 & & \\
\hline P. falciparum & 80 & 92 & & & \\
\hline P. ovale & 63 & $\begin{array}{l}34 \text { P. ovale curtisi, } 24 \text { P. ovale } \\
\text { wallikeri }\end{array}$ & & & 57 \\
\hline P. vivax & 61 & 87 & & 87 & \\
\hline P. malariae & 4 & 4 & & & \\
\hline Negative & 71 & 38 & 38 & 192 & 222 \\
\hline Total & 279 & 279 & 279 & 279 & 279 \\
\hline Primers & Sensitivity & & Specificity & $\begin{array}{l}\mathrm{LO} \\
\mu \mathrm{L}\end{array}$ & (parasites/ \\
\hline Malaria Pan & \multicolumn{2}{|c|}{ 100\% (95\% Cl 98.48-100\%) } & $100 \%$ (95\% Cl 90.75-100\%) & \multicolumn{2}{|c|}{$3.73 \pm 0.33$} \\
\hline P. vivax & \multicolumn{2}{|c|}{ 100\% (95\% Cl 95.85-100\%) } & 100\% (95\% Cl 98.1-100\%) & \multicolumn{2}{|c|}{$3.79 \pm 0.71$} \\
\hline P.ovale & \multicolumn{2}{|c|}{ 98.28\% (95\%Cl: 90.76-99.96\%) } & $100 \%$ (95\% Cl 98.34-100\%) & \multicolumn{2}{|c|}{$4.15 \pm 0.36$} \\
\hline
\end{tabular}

$\mathrm{Cl}$, Confidence interval; LOD, limit of detection

Table 3 Correspondence of three assays for detecting Plasmodium infections

\begin{tabular}{lcll}
\hline Plasmodium genus & \multicolumn{2}{l}{ Number of cases } \\
\cline { 2 - 4 } & Nested PCR & $\begin{array}{l}\text { mtDNA } \\
\text { Malaria Pan } \\
\text { LAMP }\end{array}$ & $\begin{array}{l}\text { Malaria genus-specific } \\
\text { LAMP patent primer } \\
\text { (Japan) }\end{array}$ \\
\hline Positive & 25 & 25 & 24 \\
Negative & 5 & 5 & 6 \\
Total & 30 & 30 & 30 \\
$P$ value & & $<0.01$ & $<0.01$ \\
\hline
\end{tabular}

Previously described LAMP primers [14] were applied to 30 randomly selected clinical samples, yielding a sensitivity of $93 \%$ (95\% confidence interval [CI] 74.97-99.02\%) and a specificity of $80 \%$ (95\% CI 78.88-99.89\%). Among 25 positive samples, one sample infected with $P$. falciparum and one sample infected with $P$. ovale wallikeri tested negative with the previously reported LAMP assay. This assay assessed four of the five negative samples as uninfected (Table 3). Thus, these primers afforded lower sensitivity and specificity than the newly described LAMP assay.

\section{Discussion}

The World Health Organization has targeted malaria for eradication by 2030 . The prevalence of malaria has been declining over the long term, but no significant progress in case reduction has been accomplished in the past 4 years [24] and 57 persons per 1000 general population were still at risk of infection in 2018 [1].
Rapid diagnosis plays an important role in pursuing this goal of total malaria eradication. The traditional microscopic examination method is still widely used in many malaria-endemic areas due to limited public health/medical facilities and lower economic levels; in addition, technical proficiency is required. In our study, microscopy was found to be less sensitive and less specific than the newly described LAMP tests. Technical experience of local operators and existence of submicroscopic malaria greatly impacted the accuracy of detection. LAMP and PCR identified infection in some clinical samples in which no blood-stage parasites were detected by microscopy.

LAMP, as a new and easy-to-operate molecular diagnostic method, has the potential to be broadly applied and is considered to have the possibility of replacing the classic PCR method. Our specific aim was to detect, with requisite sensitivity and specificity, those infections capable of persisting as hypnozoites. The elimination of these liver stages of $P$. vivax and $P$. ovale is important to preclude clinical relapse. The target gene sequence $m t D N A$ of the Malaria Pan LAMP assay occurs as $30-150$ copies per parasite; the $18 S$ rDNA of $P$. vivax and $P$. ovale is present as four to eight copies per parasite. Intraspecific sequence conservation has been confirmed for each species $[22,24$, 25].

A previous report [20] warned of cross-reactions ensuing from the LAMP primers described by Han et al. [16]. We found that these genus-wide LAMP primers had a lower sensitivity and specificity. A set of Malaria Pan LAMP primer targeting the $18 S \mathrm{rDNA}$ 
sequence carried out in Malaysia had comparable sensitivity and specificity to our assay [23]. The reported LOD was lower than that of our assay and values reported previously; indeed, a LOD of only one copy raises concerns of reproducibility [26, 27].

The commercially available Eiken Loopamp ${ }^{\text {TM }}$ MALARIA Pan Detection Kit targeting the $18 \mathrm{~S}$ rDNA sequence with $83.4 \%$ sensitivity and $81.58 \%$ specificity was found not to be suitable for clinical diagnosis; in particular, its sensitivity was only $50 \%$ when parasitemia was $<50$ parasites/ $\mu$ l blood [20]. Although the commercially available Illumigene Malaria Plus test targeting mtDNA sequence showed good sensitivity and specificity of > $98 \%$, respectively [28], it has been reported to have false negative tests in cases where parasitemia with $P$. falciparum exceeded $1 \%$ [20].

The performance of our $18 S$ rDNA P. vivax LAMP with $100 \%$ sensitivity and $100 \%$ specificity and $18 S$ rDNA $P$. ovale LAMP with $100 \%$ sensitivity and $100 \%$ specificity was also similar or better than previous reported species-specific LAMP assays [20, 24, 26]. The LOD of our Malaria Pan LAMP, $P$. vivax LAMP and $P$. ovale LAMP was 3-4 parasites/ $\mu \mathrm{l}$, which is close to the LOD of nested PCR; previous reports have found comparable sensitivities of other LAMP assays [29]. Compared to the LOD of the PCR assay $\left(10^{3}\right.$ copies $\left./ \mu \mathrm{l}\right)$, the LODs of our Malaria Pan LAMP $\left(10^{2}\right.$ copies/ $\left.\mu \mathrm{l}\right)$ and $P$. vivax LAMP $\left(10^{2}\right.$ copies/ $\mu \mathrm{l})$ were 100 -fold lower, and of our P. ovale LAMP, tenfold lower $\left(10^{4}\right.$ copies $\left./ \mu \mathrm{L}\right)$. These results are similar to those reported previously for other LAMP assays [26, 27].

The primers used in the present study differ from previous assays (Additional file 1: Table S1) and have shown high sensitivity and specificity. For the first time, LAMP was evaluated for its diagnostic performance of $P$. ovale in a large-scale study (279 clinical samples). Reported infections with $P$. ovale and $P$. vivax have increased among Chinese migrant laborers in Africa [30-39]. The performance and convenience of the novel LAMP assays described here offer promise as tools for clinical diagnosis and epidemiological surveys. In cases where parasites in the genus Plasmodium have first been identified, differential diagnosis can then be accomplished using species-specific assays for $P$. vivax and $P$. ovale.

\section{Conclusions}

We have described three sets of novel LAMP assays for the detection of malaria. The first, targeting a conserved portion of the $m t D N A$ gene, detects all five malaria species known to infect people. The other two, targeting portions of the $18 S$ rDNA gene, specifically amplify $P$. vivax or $P$. ovale, the two species prone to persisting as hypnozoites and causing clinical relapse if not recognized and eliminated through chemotherapies directed at those liver stages.

We have shown that these assays are highly sensitive and specific when applied to defined control templates and clinical isolates. The assays are easy to perform and require no complicated experimental equipment. This diagnostic approach can assist a wide range of research and clinical applications.

\section{Abbreviations}

LAMP: Loop-mediated isothermal amplification; LOD: Limit of detection; mtDNA: Mitochondrial DNA gene; 185 rDNA: Nuclear 185 ribosomal RNA gene.

\section{Supplementary Information}

The online version contains supplementary material available at https://doi. org/10.1186/s13071-021-04764-9.

Additional file 1: Table S1. Plasmodium falciparum, P. vivax, P. ovale curtisi, P.ovale wallikeri, P. malariae and P. knowlesi mtDNA sequences, P. vivax 185 rRNA sequences and $P$. ovale curtisi, P. ovale wallikeri 185 rDNA sequences.

\section{Acknowledgements}

First and foremost, we thank all the patients that donated blood for volunteering to participate in the study. We thank laboratory staffs for culturing $P$. falciparum 3D7. We acknowledge MR4 for donation of malaria parasites ( $P$. knowlesi).

\section{Authors' contributions}

$X C, J Z, Y H$ and $Z Y$ conceived and designed the experiments. XC, JZ, MP, YQ, $H Z, P Q, Q Y, Y Z$ and $W Z$ performed the experiments. $X C, J Z, W Z, Z X, M D, X L$ and $X W$ contributed materials and analysis tools. $X C, Z Y, D M$ and BMR wrote and edited the paper. All authors read and approved the final manuscript.

\section{Funding}

This study was supported by the National Science Foundation of China (31860604 and U1802286), Major science and technology projects of Yunnan Province (2018ZF0081) and International Science and Technology Cooperation-Yunnan International Science and Technology Cooperation Base (202003AE140004). XC, ZX and YZ were working under the sponsorship of the Yunnan Applied Basic Research Projects-Union Foundation (2018FE001-190, 2019FE001-015 and 2015FB034 respectively). YQ was supported by Guangxi Zhuang Autonomous Region Health Commission of Scientific Research Project (Z20190892). WZ was supported by the Education Department Fund of Yunnan Province (2019J1184).

\section{Availability of data and materials}

All data generated or analyzed during this study are included in this published article and its supplementary information file. The datasets of clinical malaria samples used and analyzed during the present study are available from the corresponding author on reasonable request. 


\section{Declarations}

\section{Ethics approval and consent to participate}

We used clinical samples obtained from the Department of Infectious Diseases in Shanglin Hospital, Shanglin County, Guangxi Province, China and from the Malaria surveillance clinic, Tengchong County (China-Myanmar border), Yunnan Province, China. The clinical subjects were Chinese migrant workers who had returned from Africa or Myanmar. This study was approved by the Ethics Review Committees of Institutional Review Board (IRB) of Shanglin Hospital and Institutional Review Board of Kunming Medical University, Yunnan Province, China. All participants provided written informed consent: written informed consent was obtained from either the patients themselves or from the guardians of patients who were minors at the time of the study.

\section{Consent for publication}

Not applicable.

\section{Competing interests}

The authors affirm that they have no conflict of interest. The novel primers of malaria Pan mtDNA LAMP, 185 rDNA P. vivax and 185 rDNA P. ovale LAMP in our assay were included in Patent No: 201910611312.9 (China), citing XC, JZ, and $Z Y$ as inventors.

\section{Author details}

'Laboratory of Pathogen Biology and Immunology, Kunming Medical University, Kunming 650500, Yunnan, People's Republic of China. ${ }^{2}$ Department of Pathogen Biology and Immunology, Kunming Medical University, Kunming 650500, Yunnan, People's Republic of China. ${ }^{3}$ Zhejiang Provincial Center for Disease Control and Prevention, No. 3399 BinSheng Road, Binjiang District, Hangzhou 310051, Zhejiang, People's Republic of China. ${ }^{4}$ Shanglin County People's Hospital, Shanglin 530500, Guangxi, People's Republic of China. ${ }^{5}$ INSERM, CNRS, Centre d'Immunologie et des Maladies Infectieuses (CIMI), Sorbonne Université, 75013 Paris, France. ${ }^{6}$ Animal Parasitic Disease Laboratory, USDA-Agricultural Research Service, 10300 Baltimore Avenue, Beltsville, MD 20705, USA. ${ }^{7}$ Guangxi Zhuang Autonomous Region Center for Disease Prevention and Control, Nanning 530021, Guangxi, People's Republic of China.

Received: 9 December 2020 Accepted: 3 May 2021

Published online: 24 May 2021

\section{References}

1. World Health Organization. World malaria report 2019. https://www.who. int/malaria/publications/world-malaria-report-2019/en/. Accessed 3 Dec 2019

2. Kumar R, Saravu K. Severe vivax malaria: a prospective exploration at a tertiary healthcare centre in Southwestern India. Pathog Glob Health. 2017;111:148-60.

3. Groger M, Fischer HS, Veletzky L, Lalremruata A, Ramharter M. A systematic review of the clinical presentation, treatment and relapse characteristics of human Plasmodium ovale malaria. Malar J. 2017:16:112.

4. Stephens JWW. A new malaria parasite of man. Ann Trop Med Parasitol. 1922:16:383-8.

5. Mikolajczak SA, Vaughan AM, Kangwanrangsan N, Roobsoong W, Fishbaugher $\mathrm{M}$, Yimamnuaychok $\mathrm{N}$, et al. Plasmodium vivax liver stage development and hypnozoite persistence in human liver-chimeric mice. Cell Host Microbe. 2015;17:526-35.

6. Erdogan E, Yuruk M, Sivcan E, Karaca S, Yildiz O, Sahin I. Plasmodium ovale malaria and molecular diagnosis: could it be a relapse? Mikrobiyol Bull. 2019:53:106-13.

7. World Health Organization. Guidelines for the treatment of malaria. 3rd ed. Geneva: World Health Organization; 2015.

8. Bialasiewicz S, Whiley DM, Nissen MD, Sloots TP. Impact of competitive inhibition and sequence variation upon the sensitivity of malaria PCR. J Clin Microbiol. 2007:45:1621-3.
9. Siwal N, Singh US, Dash M, Kar S, Rani S, Rawal C, et al. Malaria diagnosis by $P C R$ revealed differential distribution of mono and mixed species infections by Plasmodium falciparum and P. vivax in India. PLoS ONE. 2018;13:e0193046.

10. Jiram Al, Ooi CH, Rubio JM, Hisam S, Karnan G, Sukor NM, et al. Evidence of asymptomatic submicroscopic malaria in low transmission areas in Belaga district, Kapit division, Sarawak, Malaysia. Malar J. 2019:18:156.

11. Mukkala AN, Kwan J, Lau R, Harris D, Kain D, Boggild AK. An update on malaria rapid diagnostic tests. Curr Infect Dis Rep. 2018:20:49.

12. Komaki-Yasuda K, Vincent JP, Nakatsu M, Kato Y, Ohmagari N, Kano S. A novel PCR-based system for the detection of four species of human malaria parasites and Plasmodium knowlesi. PLoS ONE. 2018;13:e0191886.

13. Shah J, Mark O, Weltman H, Barcelo N, Lo W, Wronska D, et al. Fluorescence in situ hybridization (FISH) assays for diagnosing malaria in endemic areas. PLoS ONE. 2015;10:e0136726.

14. Shah J, Poruri A, Mark O, Khadilka U, Mohring F, Moon RW, et al. A dual colour fluorescence in situ hybridization (FISH) assay for identifying the zoonotic malaria parasite Plasmodium knowlesi with a potential application for the specific diagnosis of knowlesi malaria in peripheral-level laboratories of Southeast Asia. Parasites Vectors. 2017;10:342.

15. Notomi T, Okayama H, Masubuchi H, Yonekawa T, Watanabe K, Amino N, et al. Loop-mediated isothermal amplification of DNA. Nucleic Acids Res. 2000;28:E63.

16. Han ET, Watanabe R, Sattabongkot J, Khuntirat B, Sirichaisinthop J, Iriko $\mathrm{H}$, et al. Detection of four Plasmodium species by genus- and speciesspecific loop-mediated isothermal amplification for clinical diagnosis. J Clin Microbiol. 2007:45:2521-8.

17. Becker S. LAMP - an innovative POC tool for diagnosing pulmonary TB in remote areas. Indian J Tuberc. 2017;64:72-6.

18. Cao L, Cheng R, Yao L, Yuan S, Yao X. Establishment and application of a loop-mediated isothermal amplification method for simple, specific, sensitive and rapid detection of Toxoplasma gondii. J Vet Med Sci. 2014:76:9-14.

19. Adao DE, Rivera WL. Loop-mediated isothermal amplification (LAMP) assay for the rapid detection of the sexually-transmitted parasite, Trichomonas vaginalis. Ann Parasitol. 2016;62:25-31.

20. Kollenda H, Hagen RM, Hanke M, Rojak S, Hinz R, Wassill L, et al. Poor diagnostic performance of a species-specific loop-mediated isothermal amplification (LAMP) platform for malaria. Eur J Microbiol Immunol. 2018;8:112-8.

21. Johnston SP, Pieniazek NJ, Xayavong MV, Slemenda SB, Wilkins PP, da Silva AJ. PCR as a confirmatory technique for laboratory diagnosis of malaria. J Clin Microbiol. 2006;44:1087-9.

22. Miller RH, Obuya CO, Wanja EW, Ogutu B, Waitumbi J, Luckhart S, et al. Characterization of Plasmodium ovale curtisi and P. ovale wallikeri in Western Kenya utilizing a novel species-specific real-time PCR assay. PLoS Negl Trop Dis. 2015;9:e0003469.

23. Lau YL, Lai MY, Fong MY, Jelip J, Mahmud R. Loop-mediated isothermal amplification assay for identification of five human Plasmodium species in Malaysia. Am J Trop Med Hyg. 2016;94:336-9.

24. Dinzouna-Boutamba SD, Yang HW, Joo SY, Jeong S, Na BK, Inoue N, et al. The development of loop-mediated isothermal amplification targeting al pha-tubulin DNA for the rapid detection of Plasmodium vivax. Malar J. 2014;13:248.

25. Echeverry DF, Deason NA, Davidson J, Makuru V, Xiao H, Niedbalski J, et al. Human malaria diagnosis using a single-step direct-PCR based on the Plasmodium cytochrome oxidase III gene. Malar J. 2016;15:128.

26. Tao ZY, Zhou HY, Xia H, Xu S, Zhu HW, Culleton RL, et al. Adaptation of a visualized loop-mediated isothermal amplification technique for field detection of Plasmodium vivax infection. Parasites Vectors. 2011:4:115.

27. Iseki H, Kawai S, Takahashi N, Hirai M, Tanabe K, Yokoyama N, et al. Evaluation of a loop-mediated isothermal amplification method as a tool for diagnosis of infection by the zoonotic simian malaria parasite Plasmodium knowlesi. J Clin Microbiol. 2010:48:2509-14. 
28. Frickmann H, Hinz R, Rojak S, Bonow I, Ruben S, Wegner C, et al. Evaluation of automated loop-mediated amplification (LAMP) for routine malaria detection in blood samples of German travelers - a cross-sectional study. Travel Med Infect Dis. 2018;24:25-30.

29. Chen JH, Lu F, Lim CS, Kim JY, Ahn HJ, Suh IB, et al. Detection of Plasmodium vivax infection in the Republic of Korea by loop-mediated isothermal amplification (LAMP). Acta Trop. 2010;113:61-5.

30. Dong Y, Deng Y, Xu Y, Chen M, Wei C, Zhang C, et al. Analysis of initial laboratory diagnosis of malaria and its accuracy compared with re-testing from 2013 to 2018 in Yunnan Province, China. Malar J. 2020;19:409.

31. Zhang T, Wang S, Wang D, Auburn S, Lu S, Xu X, et al. Epidemiological profile of Plasmodium ovale spp. imported from Africa to Anhui Province, China, 2012-2019. Malar J. 2021;20:15.

32. Sun LC, Dong XR, Tu Z, Wu DN, Lin W, Zhou XR, et al. Re-examination of malaria diagnosis in Hubei Provincial malaria diagnostic reference laboratory from 2017 to 2019. Zhongguo Xue Xi Chong Bing Fang Zhi Za Zhi. 2020;32:631-4.

33. Xiao LZ, Ouyang R, Xie HG, Chen ZY, Lin YY, Zhang SY. Epidemiological characteristics of imported malaria cases in Fujian Province from 2014 to 2018. Zhongguo Xue Xi Chong Bing Fang Zhi Za Zhi. 2020;32:401-4.

34. Xie Y, Wu K, Cheng W, Jiang T, Yao Y, Xu M, et al. Molecular epidemiological surveillance of Africa and Asia imported malaria in Wuhan, central China: comparison of diagnostic tools during 2011-2018. Malar J. 2020;19:321.
35. Xia J, Wu D, Sun L, Zhu H, Li K, Zhang J, et al. Characteristics of imported Plasmodium ovale spp. and Plasmodium malariae in Hubei Province, China, 2014-2018. Malar J. 2020;19:264.

36. Yu T, Fu Y, Kong X, Liu X, Yan G, Wang Y. Epidemiological characteristics of imported malaria in Shandong Province, China, from 2012 to 2017. Sci Rep. 2020;10:7568.

37. Wang WM, Cao YY, Yang MM, Gu YP, Xu S, Zhou HY, et al. Epidemic situation of malaria in Jiangsu Province in 2018. Zhongguo Xue Xi Chong Bing Fang Zhi Za Zhi. 2019;31:649-51.

38. Li W, Zhang T, Xu X, Jiang J, Yu C, Tian C, et al. Problems associated with the diagnosis of imported malaria in Anhui Province, China. Am J Trop Med Hyg. 2020;102:142-6.

39. Yan-Feng G, Lei L, Zhi-Hong L, Jun SG, Jian-Gang Z. Spatial_-temporal distribution of malaria in Jiangxi Province from 1950 to 2017. Zhongguo Xue Xi Chong Bing Fang Zhi Za Zhi. 2019;31:414-7.

\section{Publisher's Note}

Springer Nature remains neutral with regard to jurisdictional claims in published maps and institutional affiliations.
Ready to submit your research? Choose BMC and benefit from:

- fast, convenient online submission

- thorough peer review by experienced researchers in your field

- rapid publication on acceptance

- support for research data, including large and complex data types

- gold Open Access which fosters wider collaboration and increased citations

- maximum visibility for your research: over 100M website views per year

At BMC, research is always in progress.

Learn more biomedcentral.com/submissions 